Washington

UniversityinSt.Louis

SCHOOL OF MEDICINE

\title{
Prostate Cancer Diagnosis
}

by Peter A. Humphrey, MD, PhD \& Gerald L. Andriole, MD

\section{Prostate cancer may be suspected by clinically- detected abnormalities in serum PSA and/or digital rectal examination, with establishment of the diagnosis by histopathologic examination of needle core tissue.}
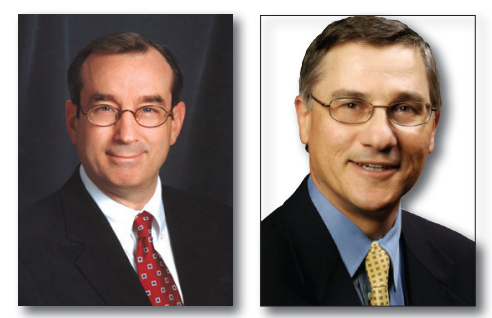

Peter A. Humphrey, MD, PhD, is Ladenson Professor and Chief of Anatomic and Molecular Pathology. Gerald L. Andriole, MD, is Robert K. Royce Distinguished Professor and Chief of Urologic Surgery; both are at Washington University School of Medicine in St. Louis.

contact: humphrey@path.wustl.edu

\begin{abstract}
Prostate cancer is the fourth most common malignancy diagnosed in Missouri. The diagnosis may be clinically suspected based on an elevated serum prostate specific antigen (PSA) and/or digital rectal examination abnormality. Clinical symptoms are usually a manifestation of more advanced disease. The diagnosis is typically established by histopathologic examination of needle biopsy tissue. This article reviews clinical and pathological approaches to prostate cancer diagnosis, with a focus on clinically localized disease and needle biopsy diagnosis.
\end{abstract}

\section{Introduction}

Prostate cancer is a major health problem in Missouri, with an estimated 3,050 new cases diagnosed in 2008 . $^{1}$

Prostate cancer is the fourth most common cancer in Missouri, after lung, breast, and colorectal cancer. It is the sixth leading cause of death due to cancer in Missouri.

The clinical approach to the diagnosis of prostate cancer has changed significantly over time. In years prior to the introduction of serum PSA in the late 1980s, prostatic carcinoma was diagnosed by symptoms, by digital rectal examination, or as an incidental histologic finding in prostatic chips from transurethral resection of the prostate performed for benign prostatic hyperplasia (BPH). In this current era, most men in the United States who are diagnosed with prostate cancer are asymptomatic, and prostate cancer is clinically detected by abnormalities in serum prostate specific antigen (PSA) level and/or digital rectal examination (DRE). Serum PSA elevation and/ or DRE abnormality prompts performance of transrectal ultrasoundguided prostate needle biopsy, typically with procurement of 10-12 cores.

Histopathologic examination of needle core sections is the definitive procedure for establishment of the diagnosis of prostate cancer.

There have been many recent advances in the use of serum PSA, in needle biopsy methodologies, and in diagnosis and grading of prostate cancer in needle core tissue. The aim of this review is to discuss current clinical approaches to prostate cancer diagnosis, and histopathologic needle biopsy diagnosis, along with the clinical implications of the pathological features of the cancer in prostate needle biopsy tissue.

\section{Clinical Symptoms}

Prostatic carcinoma generally does not cause symptoms until late in the course of the disease., ${ }^{2,3}$ Local symptoms can mimic benign prostatic hyperplasia $(\mathrm{BPH})$, with an increase in frequency 
and difficulty in urination. Acute urinary retention and hematuria are uncommon in patients with prostate cancer and are also nonspecific. Hematospermia is rare and is caused by destruction of the ejaculatory ducts. Impotence can result from posterolateral extraprostatic extension of carcinoma into the adjacent neurovascular bundles. Rectal invasion, priapism, and uremia (due to renal failure secondary to ureteral obstruction) are rare, late manifestations of highly advanced local disease. ${ }^{3}$

The first symptoms of prostate cancer can be caused by metastasis. Regional pelvic lymph nodes and bones are the anatomic sites most commonly involved by metastatic spread, but only bone involvement consistently produces significant symptoms. ${ }^{3}$ Thus, patients can present with pain in the lower back, chest and upper back, hip, leg, and shoulder caused by carcinoma in the spine, ribs, pelvis, femur, and shoulder bones, respectively. Infrequently, pathologic fractures due to metastatic spread to bones occur. Neurologic symptoms are a common complaint in patients with metastatic disease but are not usually presenting symptoms. Rarely, spread to other sites can cause symptoms, and this usually occurs in the setting of known, widely disseminated disease. Hematologic abnormalities associated with metastatic prostatic carcinoma are uncommon and include anemia and disseminated intravascular coagulopathy. ${ }^{3}$

\section{Digital Rectal Examination}

Digital palpation of the prostate via the rectum has long been an important clinical tool in detecting prostatic carcinoma. A Digital Rectal Examination (DRE) suspicious for malignancy is not particularly sensitive, nor is it specific, for a diagnosis of carcinoma. The DRE is suspicious for malignancy in about $7 \%$ of all screened men. ${ }^{4}$ DRE has a lower positive predictive value than serum PSA for detection of carcinoma and misses onequarter to one-half of prostate cancers detected by prostate biopsy done for serum PSA elevation. ${ }^{4}$ The positive predictive value of the DRE depends on the PSA level, race, and age. ${ }^{4}$ DRE is subjective, with significant interexaminer variability. Advocates of early detection of prostate cancer recommend using both serum PSA and DRE.

Prostatic carcinomas detected by DRE are often more advanced than those detected by serum PSA elevation. ${ }^{5}$ Clinically localized cancer is found in about $65 \%$ of patients with an abnormal DRE, but histopathologic study of radical prostatectomy specimens from these men reveals extraprostatic extension in up to $66 \% .^{5}$ That is, by the time a prostate cancer is palpable, it is more likely than not to have already spread beyond the confines of prostate gland. In radical prostatectomy tissue, DRE-detected carcinomas are, on average, twice the size of PSA-detected carcinomas and are more likely to exhibit extraprostatic extension, seminal vesicle invasion, and positive surgical margins. $^{5}$

\section{Serum Prostate-Specific Antigen (PSA)}

Serum PSA is currently the most important tumor marker for adenocarcinoma of the prostate, and has a vital role, despite some serious limitations, in detection, staging, and post-therapy monitoring of prostate cancer. ${ }^{6-8}$ In the current era, most men with prostate cancer have clinically impalpable carcinoma with an elevated serum PSA between 2.5 and $10 \mathrm{ng} / \mathrm{ml}$. PSA can also be found in the urine, but this assay is not of established diagnostic value.

Serum PSA elevations are not specific for a histologic diagnosis of prostatic adenocarcinoma. Indeed, most (up to $75 \%$ of) men with an elevated serum PSA do not have prostate cancer, but rather another abnormality, especially BPH and/or prostatic inflammation. $\mathrm{BPH}$ is the most common cause of an elevated PSA and probably accounts for $60 \%$ to $70 \%$ of cases of an elevated serum PSA. Additional benign entities that can cause an elevated serum PSA include prostatic inflammation and infarction.

The positive predictive value of an elevated serum PSA for the detection of prostate cancer depends on the definition of the optimal upper limit of normal. ${ }^{6,8}$ Above $4 \mathrm{ng} / \mathrm{ml}$, the positive predictive value for a histologic diagnosis of carcinoma in needle biopsy is 31 $51 \%$. However, detection rates are 10\% at 0.6 to $1.0 \mathrm{ng} / \mathrm{ml}, 17 \%$ at 1.1 to 2.0 $\mathrm{ng} / \mathrm{ml}, 24 \%$ at 2.1 to $3.0 \mathrm{ng} / \mathrm{ml}$, and $27 \%$ at 3.1 to $4.0 \mathrm{ng} / \mathrm{ml} .{ }^{9}$ Moreover, $13 \%$ to $25 \%$ of these cancers detected below $4 \mathrm{ng} / \mathrm{ml}$ are high histologic Gleason grade (a score of 7 or more). These data have created the challenge of setting a lower limit cutpoint for a "normal" total PSA level. At very high levels of serum PSA, above $10 \mathrm{ng} / \mathrm{ml}$, the probability of carcinoma detection is up to $60 \%$, but most men present with levels below $10 \mathrm{ng} / \mathrm{ml}$.

PSA assay variations have been developed to attempt to improve the positive predictive value of total serum PSA level. These permutations include PSA density (serum PSA $\div$ ultrasound volume of the prostate gland), PSA velocity (rate of change of PSA over time), age-specific PSA levels, percent free (uncomplexed) PSA, complexed PSA, prePSA, and BPSA. PSA velocity (of $>0.75 \mathrm{ng} / \mathrm{ml} /$ year) is related to prostate cancer presence, and a rise of $>2 \mathrm{ng} / \mathrm{ml} /$ year is associated with more aggressive prostate cancer. ${ }^{10}$ Percent free PSA can help in counseling men with total PSA between 4 and 10ng/ml 
regarding their risk of prostate cancer. ${ }^{6}$

Total serum PSA has been used in screening to diagnose prostate cancer. Two large prospective randomized clinical screening trials, the Prostate, Lung, Colorectal and Ovarian (PLCO) trial and the European Randomized Study of Screening for Prostate Cancer (ERSPC), are in progress. Data from the PLCO trial demonstrate that $8 \%$ of over 38,000 screened men had an elevated serum PSA of $>4 \mathrm{ng} / \mathrm{ml}$ and $1.4 \%$ were diagnosed with prostate cancer by histological examination of needle core sections. ${ }^{11}$ In the PLCO trial, prostate cancer screening provided no reduction in cancer-specific death rates at 7 to 10 years, while in the ERSPC trial, a significantly larger study, PSA screening was associated with a $20 \%$ relative reduction in the death rate from prostate cancer at a median follow-up of 9 years. ${ }^{12}$ Longer term follow-up of the two screening trials will be important to determine impact of screening on longer-term mortality. Neither trial was perfect. PLCO results may be confounded by contamination (that is, PSA testing) in the control arm, thus lowering the probability of observing a relative survival benefit among men in the screened arm. ERSPC can be faulted in that men in the screened arm generally received their biopsy and treatment at larger medical centers, while those randomized to the control arm were evaluated in more rural, community settings where the prevailing approach to biopsy and treatment was generally far less aggressive. There appear to be substantial differences between the 2 ERSPC arms; for example, the rate of radical prostatectomy was more than 2.8 times higher in the screened arm than the control arm. This is an important consideration, as it is now apparent that the fall in prostate cancer mortality observed in the USA in the early 1990s could not have been due to the introduction of PSA screening, as neither PLCO or ERSPC showed an early survival advantage. Therefore the drop in prostate cancer mortality observed in the USA in the 1990s must have been due to the more widespread implementation of more aggressive treatment. This has caused concern that the mortality benefit in the ERSPC trial is also due to the substantial treatment differences between the 2 arms and not due to PSA testing.

Prostate cancer screening remains controversial and some professional organizations such as the US Preventive Task Force do not support routine testing for prostate cancer. The American Cancer Society recommends that PSA testing be offered to men over $50 .{ }^{13}$ For men at high risk (AfricanAmerican men and men with a positive family history), it has been suggested that testing could begin at a younger age (45 years).

New serum and urine-based biomarkers for prostate cancer are being developed since PSA lacks specificity for prostate cancer and since serum PSA elevations are seen with both non-aggressive and aggressive prostate cancers. What is needed is a biomarker that allows for diagnosis of aggressive, rather than all prostate cancers.

\section{Prostate Needle Biopsy Procedure}

The optimal biopsy sampling maneuver entails procurement of 10 to 12 cores via systematic needle core placement under transrectal ultrasound guidance. In the past, this has been accomplished using a hand-held 2 dimensional ultrasound probe. This approach has long been known to be sub-optimal, as rebiopsy of men whose initial biopsy was negative shows prostate cancer 20 to $35 \%$ of the time. The most likely explanation for this finding is that the biopsy cores of the initial biopsy were symmetrically arrayed, and hence, some parts of the prostate were not sampled. Recently, three-dimensional mapping has been introduced to minimize this occurrence. One approach to prostate mapping uses a novel transrectal ultrasound device that has been shown to produce a higher cancer detection rate with a more accurate assessment of histologic Gleason grade and tumor location within the prostate. ${ }^{14}$ An alternative approach is to attach a standard 2-dimensional probe to a "stepper" unit that controls the insertion depth of the probe, thereby allowing more precise transperineal biopsies. The latter approach generally requires sedation or light anesthesia.

\section{Histologic Diagnosis of Prostate Cancer in Needle Biopsy Tissue}

The diagnosis of prostatic carcinoma in needle biopsy tissue is established by light microscopic examination of hematoxylin and eosin-stained sections of formalinfixed, paraffin-embedded needle cores. The histopathological diagnosis of malignancy is based on a constellation of histological findings. ${ }^{15}$ First, there is a disordered architecture, often with a crowded and infiltrative arrangement of malignant glands (adenocarcinoma) (See Figure 1). Secondly, the malignant glands lack a basal cell layer, which is an indication of invasion. Third, the neoplastic cells display cytologic abnormalities, including nuclear atypia, in the form of nuclear enlargement and large nucleoli (See Figure 2). Highergrade adenocarcinomas have diminished differentiation capacity and lose the ability to form glandular luminal spaces, and can grow as single cells, sheets, or cords (See Figure3). Discoveries in molecular medicine and pathology have had an impact on diagnosis of 


\section{Figure 1}

Adenocarcinoma of the prostate, Gleason grade $3+3$

$=$ score of 6 , in needle core biopsy tissue (H \& E stain)

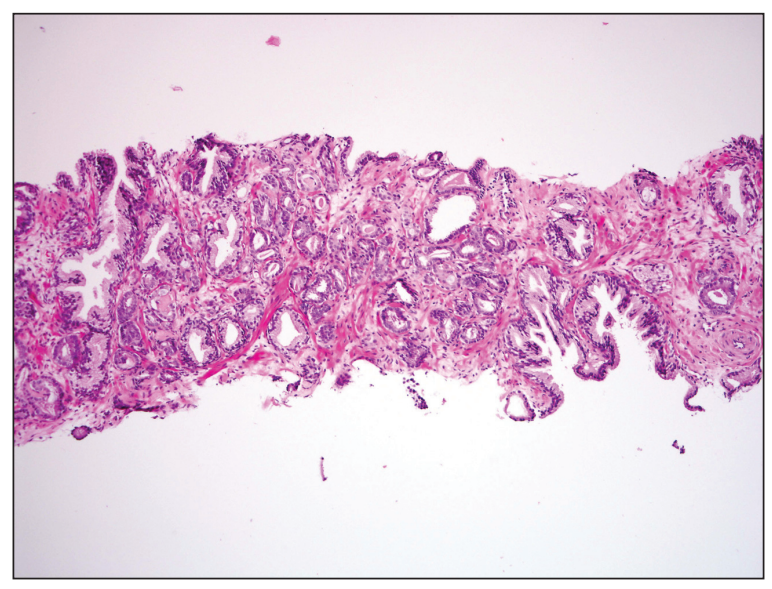

Figure 3

High-grade prostatic adenocarcinoma, Gleason grade 5 $+5=$ score of 10 , with sheet-like growth (left), adjacent to benign prostatic gland (right). (H and E stain).

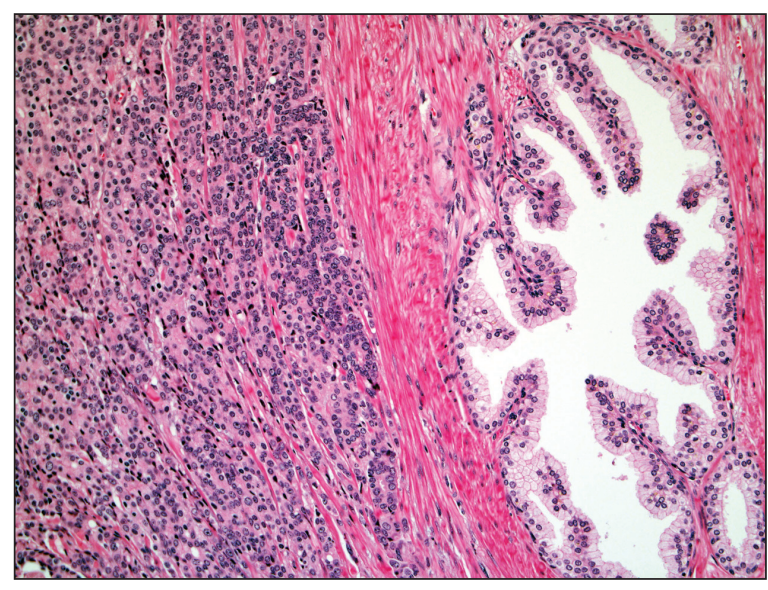

Figure 2

Nuclear atypia in high-grade adenocarcinoma of the prostate, with prominent nucleoli. (H \&E stain).

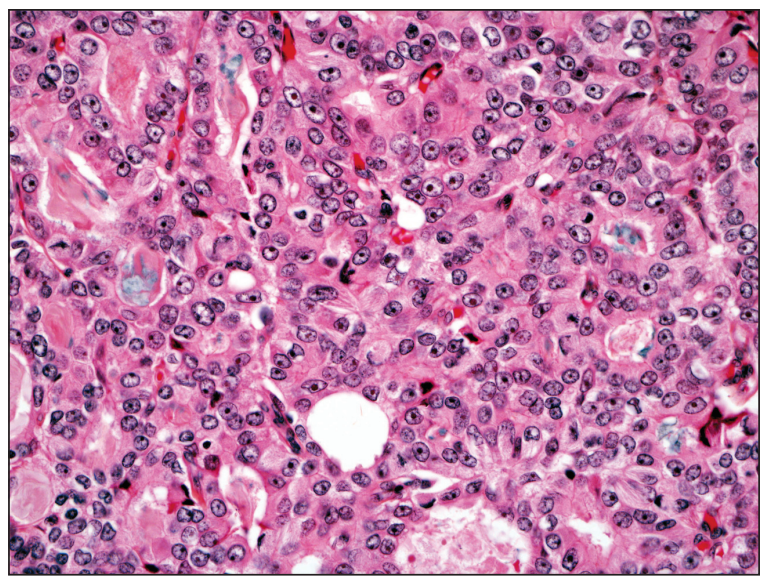

Figure 4

Small focus of adenocarcinoma with AMACR expression (red stain) surrounded by benign prostatic glands with basal cells present (brown stain).

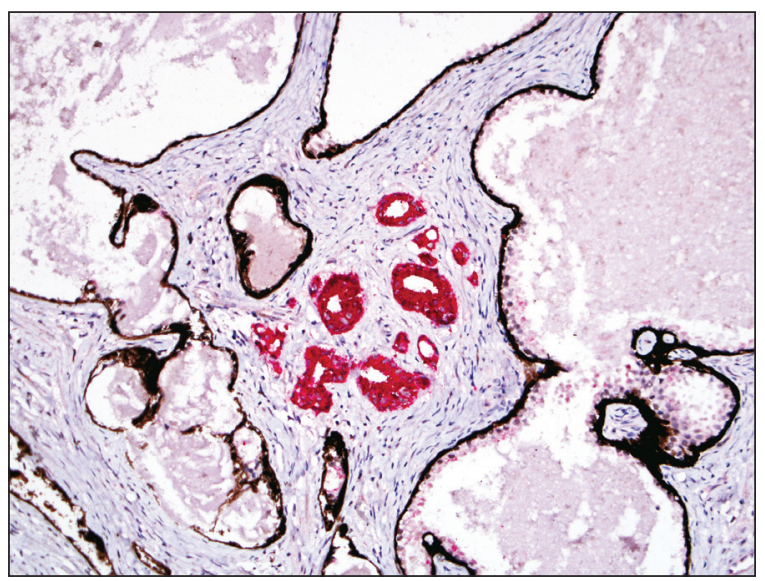

adenocarcinoma, particularly when there is only a small focus of glands that are concerning for carcinoma. In a minority of needle biopsy cases (about 10\%), immunohistochemistry for specific molecules is performed to assess for basal cell absence and over-expression of the enzyme alphamethylacyl CoA racemase (AMACR) (See Figure 4). The most commonly employed basal cell markers are p63 and high-molecular weight cytokeratin proteins. The diagnosis of malignancy in difficult cases, such as the diagnosis of very small carcinomas in needle biopsy tissue, can be supported by the finding of basal cell loss and AMACR expression. ${ }^{16}$ These immunostains are not specific for a diagnosis of malignancy and should be interpreted in the context of the features on the $\mathrm{H}$ and E-stained slides. Molecular genetic testing of prostate needle core tissue is not currently used to diagnose adenocarcinoma of the prostate (See Figure 5).

In about 3 to $5 \%$ of all needle biopsy cases, there are histological attributes that are worrisome for, but not diagnostic of malignancy. Here, a descriptive diagnosis of atypia or atypical small acinar proliferation is rendered. These patients should undergo repeat biopsy after 3 to 6 months since the risk of subsequent detection of cancer on repeat biopsy is around $45 \% .^{17}$

The surgical pathology report on adenocarcinoma in prostate needle biopsy should provide the Gleason histologic grade of the adenocarcinoma and the amount of cancer in needle 


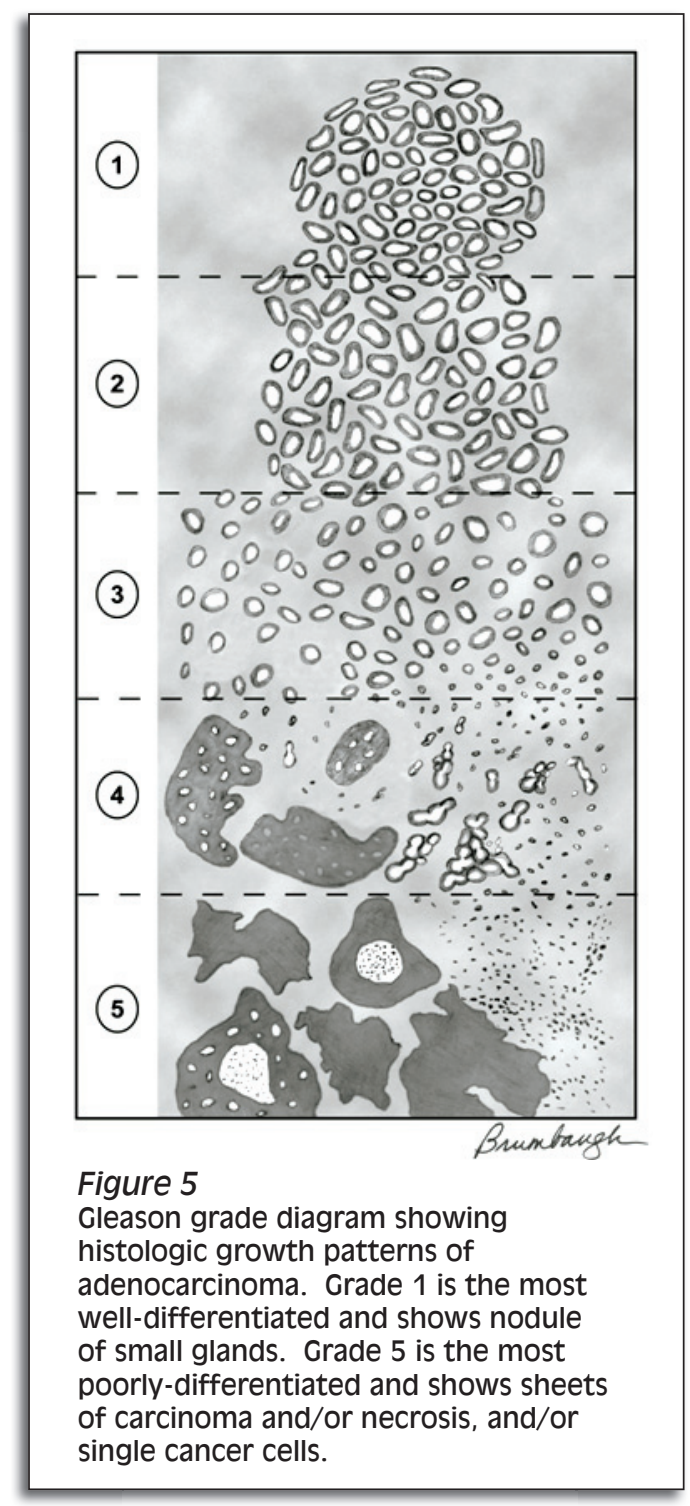

biopsy tissue. These histological parameters are critical in determination of prognosis and patient management.

\section{Gleason Grade of Prostatic Adenocarcinoma}

Gleason grade of prostatic

adenocarcinoma is one of the most important characteristics of prostate cancer in that it provides an indication of aggressiveness of the cancer. ${ }^{18}$ Gleason grade is a measure of differentiation of the cancer and is highly correlated with all important pathological and clinical endpoints such as pathological stage, response to therapy, metastasis, and cancer-specific survival. Gleason grading is performed based on the architectural growth pattern of prostatic adenocarcinoma on histopathologic examination of $\mathrm{H}$ and E-stained tissue sections. Grade should be assigned to all untreated adenocarcinomas of the prostate. Gleason grade is reported as the most common pattern and the second most common pattern, to yield the Gleason score. There are five different patterns, with increasing clinical aggressiveness and decreasing differentiation, from grade 1 to 5. The range of Gleason scores is 2 to 10 , with 2 being indolent and 10 being the most aggressive. So, for example, if Gleason grade 3 was the predominant pattern and Gleason grade 4 was a minor component, then the diagnosis in the surgical pathology report would read as follows:

Adenocarcinoma, Gleason grade $3+4=$ score of 7

In this PSA-era, most prostatic adenocarcinomas are Gleason score 6 or 7. Any high-grade Gleason grade component defined as pattern 4 or 5 , with a resultant Gleason score of 7 to 10 , is worrisome for potentially aggressive prostate cancer. Recently, it has been recognized that even a small amount of a third (tertiary) high-grade Gleason 4 or 5 pattern can adversely influence outcome. ${ }^{19}$ Needle biopsy Gleason grade does correlate with the Gleason grade in the whole prostate gland, but under-grading in needle biopsy remains a significant problem that is often due to sampling error, since the needle biopsy tissue represents such a minute amount of the whole prostate.

\section{Amount of Cancer in Prostate Needle Biopsy Tissue}

The amount of prostatic carcinoma in needle biopsy tissue is related to pathologic stage, primary tumor size, and response to therapy. The amount of cancer is reported as number of positive needle cores out of total number of cores, and percentage of prostate needle core tissue involved by carcinoma, and/ or linear mm of cancer in the needle cores.

\section{Prediction of Pathologic Stage Based on Clinical and Needle Biopsy Pathological Parameters}

Pre-treatment serum PSA level, clinical TNM stage, and Gleason grade in needle biopsy can be used to predict true pathologic stage of prostatic carcinoma. ${ }^{20}$ By plugging these three parameters into the "Partin Tables" patients and doctors can obtain estimates of the likelihood of cancer extension outside the prostate, seminal vesicle invasion, and lymph node metastasis. The probabilities can be used to counsel patients and help them make important management decisions. ${ }^{20}$ The tables are available at http://urology.jhu.edu/ prostate/partintables.php

\section{Active Surveillance Based on Clinical and Needle Biopsy Pathological Parameters}

Conservative management, with deferral of definitive therapy until evidence that the cancer is sufficiently aggressive to warrant therapy, may be appropriate for some patients with favorable (low-risk) prostate cancer. Such active surveillance should be distinguished from watchful waiting, which is no active reassessment or treatment until a patient develops 
evidence of symptomatic progression. On the other hand, active surveillance involves planned reassessment of the patient and his tumor status using physical examination, PSA (or other biomarker) testing, and periodic rebiopsy. This strategy is appropriate for men with a life expectancy of less than 10 years and for healthy men 65 years of age or older who are judged to have pathologically low-volume, low-grade prostate cancer that is potentially insignificant and clinically indolent. Commonly used criteria to identify candidates for active surveillance include serum PSA level $\leq 10 \mathrm{ng} / \mathrm{ml}$, clinical stage T1 to T2a, and needle biopsy Gleason score $\leq 6{ }^{21}$ Some protocols also incorporate PSA kinetics or derivatives, and amount of cancer in needle core tissue. ${ }^{22}$ For example, these criteria have been utilized: Gleason score of 6 or less, fewer than three cores involved by cancer, less than 50\% involvement of any core, PSA density below 0.15 or $\%$ free PSA above $15 \% .^{22}$ Patients who choose active surveillance are closely followed with a standard regimen of serum PSA testing, digital rectal examination, and repeat biopsy. Early results suggest that about onequarter of patients will "progress" to larger, or more histologically aggressive tumors within the first two to three years of surveillance. ${ }^{23}$

\section{Prediction of Response to Surgery and Radiation Therapy Based on Clinical and Needle Biopsy Pathological Parameters.}

Response to radical prostatectomy can be predicted preoperatively via use of nomograms that incorporate clinical and needle biopsy pathological findings, including preoperative serum PSA, clinical T stage, amount of cancer in needle core tissue (number of positive cores and number of negative cores) and Gleason grade in needle core tissue. ${ }^{24,25}$
Pretreatment nomograms also exist for predicting 5-year biochemical disease free recurrence probability after 3-dimensional conformal radiotherapy and after permanent brachytherapy. ${ }^{25}$ These nomograms utilize pretreatment serum PSA, needle biopsy Gleason score, clinical stage, and for external beam radiotherapy the treatment parameters of radiation dose delivered and whether neoadjuvant hormonal therapy was administered, and for brachytherapy whether external-beam radiotherapy was co-administered. ${ }^{25}$

These nomograms highlight the vital importance of Gleason grade of adenocarcinoma of the prostate, and the combined utility of clinical and needle biopsy pathological factors in determination of patient outcome after treatment. Such knowledge helps patients and physicians decide on treatment options.

\section{References}

1. Jemal A, Siegel R, Ward E, Hao Y, Xu, J, Murray T, Thun, MJ. Cancer Statistics, 2008. CA Cancer J Clin 2008; 58:71-96.

2. Carter HB, Allaf ME, Partin AW. Diagnosis and staging of prostate cancer. In: Wein AJ, ed-in-chief. Campbell-Walsh Urology. Philadelphia: Saunders Elsevier, 2007:2912-2931.

3. Kim ED, Grayhack JT. Clinical symptoms and signs of prostate cancer. In: Vogelzang NJ, Scardino PT, Shipley WU, et al, eds. Comprehensive Textbook of Genitourinary Oncology. Baltimore: Williams \& Wilkins, 1996;557-56 4. Grubb RL 3rd, Pinsky PF, Greenlee RT, Izmirlian G, Miller AB, Hickey TP, Riley TL, Mabie JE, Levin DL, Chia D, Kramer BS, Reding DJ, Church TR, Yokochi LA, Kvale PA, Weissfeld JL, Urban DA, Buys SS, Gelmann EP, Ragard LR, Crawford ED, Prorok PC, Gohagan JK, Berg $\mathrm{CD}$, Andriole GL. Prostate cancer screening in the Prostate, Lung, Colorectal and Ovarian cancer screening trial: update on findings from the initial four rounds of screening in a randomized trial. BJU Int 2008;102:1524-1530. 5. Epstein JI, Walsh PC, Carmichael M, Brendler $\mathrm{CB}$. Pathologic and clinical findings to predict tumor extent of nonpalpable (stage T1c) prostate cancer. JAMA 1994;271:368-374.

6. Gretzer MB, Partin AW. Prostate cancer tumor markers. In: Wein AJ, ed-in-chief. Campbell-Walsh Urology. Philadelphia: Saunders Elsevier, 2007,2896-2911. 7. Lilja H, Ulmert D, Vickers AJ. Prostate-specific antigen and prostate cancer: prediction, detection and monitoring. Nat Rev Cancer 2008;8:268-278.

8. Hernández J, Thompson IM. Prostate-specific antigen: a review of the validation of the most commonly used cancer biomarker. Cancer 2004;101:894-904. 9. Thompson IM, Pauler DK, Goodman PJ, Tangen CM, Lucia MS, Parnes HL, Minasian LM, Ford LG, Lippman SM, Crawford ED, Crowley JJ, Coltman CA Jr. Prevalence of prostate cancer among men with a prostate-specific antigen level $<$ or $=4.0 \mathrm{ng}$ per milliliter. N Engl J Med
2004;350:2239-2246.

10. D'Amico AV, Chen MH, Roehl KA, Catalona

WJ. Preoperative PSA velocity and the risk of death from prostate cancer after radical prostatectomy. N Engl J Med 2004;351:125-135.

11. Andriole GL, Grubb III RL, Buys SS, Chia D,

Church TR, Fouad MN, Gelmann EP, Kvale PA, Reding DJ, Weissfeld JL, Yokochi LA, Crawford ED, O'Brien B, Clapp JD, Rathmell JM, Riley TL, Hayes RB, Kramer BS, Izmirlian G, Miller AB, Pinsky PF, Prorok PC, Gohagan JK, and Berg $\mathrm{CD}$, for the PLCO Project Team. Mortality results from a randomized prostate-cancer screening trial. N Engl J Med 2009; 360:1310-1319.

12. Schroder FH, Hugosson J, Roobol MJ, Tammela TLJ, Ciatto S, Nelen V, Kwiatkowski M, Lujan M, Lilja H, Zappa M, Dennis LJ, Recker F, Berenguer A, Maattanen L, Bangma CH, Aus G, Villers A, Rebillard X, van der Kwast T, Blejenberg BG, Moss SM, de Koning HJ, and Auvinen A, for the ERSPC Investigators. Screening and prostate-cancer mortality in a randomized European study. N Engl J Med 2009; 360:1320-1328.

13. http://www.cancer.org/docroot/LRN/LRN_o. asp? dt $=36$. Finding cancer early: ACS Guidelines. 14. Megwalu II, Ferguson GG, Wei JT, Mouraviev V, Polascik TJ, Taneja S, Black L, Andriole GL, Kibel AS. Evaluation of a novel precision template-guided biopsy system for detecting prostate cancer. BJU Int 2008; 5:546-550.

15. Humphrey PA : Diagnosis of adenocarcinoma in prostate needle biopsy tissue. J Clin Pathol 2007; 60:35-42. 16. Hameed O, Humphrey PA : Immunohistochemistry in the diagnosis of minimal prostate cancer. Curr Diagn Pathol 2006; 12:279-291.

17. Epstein JI, Herawi M. Prostate needle biopsies containing prostatic intraepithelial neoplasia or atypical foci suspicious for carcinoma : implications for patient care. J Urol 2006; 175:820-834.

18. Amin MB, Grignon DJ, Humphrey PA, Srigley JR. Gleason Grading of Prostate Cancer. A contemporary approach. Philadelphia : Lippincott Williams and Wilkins, 2004

19. Patel AA, Chen M-H, Renshaw AA, D'Amico AV PSA failure following definitive treatment of prostate cancer having biopsy Gleason score 7 with tertiary grade 5. JAMA 2007; 298:1533-1538.

20. Makarov DV, Trock BJ, HumphreyEB, Mangold LA, Walsh PC, Epstein JI, Partin AW. Updated nomogram to predict pathologic stage of prostate cancer given prostatespecific antigen level, clinical stage, and biopsy Gleason score (Partin Tables) based on cases from 2000 to 2005. Urology 2007; 69:1095-1101.

21. Dall'Era MA, Cooperberg MR, Chan JM, Davies BJ, Albertsen PC, Klotz LH, Warlick CA, Holmberg L, Bailey DE Jr, Wallace ME, Kantoff PW, Carroll PR. Active surveillance for early-stage prostate cancer: review of the current literature. Cancer 2008; 112:1650-1659.

22. Epstein JI, Chan DW, Sokoll LJ, Walsh PC, Cox JL, Rittenhouse H, Wolfert R, Carter HB. Nonpalpable stage T1c prostate cancer: prediction of insignificant disease using free/total prostate specific antigen levels and needle biopsy findings. J Urol 1998;160:2407-2411.

23. Carter HB, Ketterman A, Warlick C, Metter EJ, Landis P, Walsh PC, Epstein JI. Expectant management of prostate cancer with curative intent : an update of the Johns Hopkins experience. J Urol 2007; 178:2359-2364.

24. Stephenson AJ, Scardino PT, Eastham JA, Bianco FJ Jr, Dotan ZA, Fearn PA, Kattan MW. Preoperative nomogram predicting the 10-year probability of prostate cancer recurrence after radical prostatectomy. J Natl Cancer Inst 2006;98:715-717.

25. Shariat SF, Karakiewicz PI, Roehrborn CG, Kattan. An updated catalog of prostate cancer predictive tools. Cancer 2008; 113:3075-3099.

\section{Disclosure}

None reported. 